\title{
DISSIMILAR METAL WELDS BETWEEN MARTENSITIC AND ADVANCED AUSTENITIC HIGH TEMPERATURE CREEP RESISTING STEELS - CREEP RUPTURE TEST RESULTS AND FUSION LINE INVESTIGATION ZAVARENI SPOJEVI RAZNORODNIH MARTENZITNIH I NAPREDNIH AUSTENITNIH ČELIKA OTPORNIH NA VISOKO TEMPERATURNO PUZANJE - REZULTATI ISPITIVANJA LOMA USLED PUZANJA I ISTRAŽIVANJE LINIJE STAPANJA
}

\author{
Originalni naučni rad / Original scientific paper \\ UDK / UDC: IX-2578-16.
}

Rad primljen / Paper received:

Oktobar 2017.

Ključne reči: materijali otporni na puzanje, raznorodni zavareni spojevi, ispitivanje granice puzanja i karbidi na liniji stapanja

\section{Abstract}

Modern and future power plants will use more elaborated and complex materials to withstand the higher steam temperatures and pressures as well as thermal cycling. As such, dissimilar metal welds (DMWs) will be much more widespread in new design than before and will need to demonstrate resistance to combinations of severe creep, corrosion/oxidation and low cycle fatigue. The DMWs between different steels or alloys are an underestimated topic. Experienced and documented premature failures reveal the criticality of DMWs.

This study focused on the DMWs between martensitic and advanced austenitic stainless steels. Two collaborative projects related to a $18 \% \mathrm{Cr}$ and $25 \% \mathrm{Cr}$ austenitic creep resisting stainless steel delivered data concerning base metal characterization and weldability of similar and dissimilar welding. The specific features of dissimilar welding are further approached in more detail in this analysis. Two main methodologies i.e. direct welding and buttering techniques using different filler metals were investigated and characterized via uni-axial creep rupture testing and metallographic examination particularly focusing on the fusion line carbide formation and morphology.

For the limited exposure times of $10 \mathrm{kh}$ in this project, the results show that aligned and linked up

\author{
Adresa autora / Author's address: \\ ${ }^{1}$ Engie Lab-Laborelec \\ ${ }^{2}$ BWI, Belgian Welding Institute
}

Key words: Creep resisting materials, dissimilar welds, creep rupture testing and fusion line carbides.

\section{Rezime}

Moderne i buduće elektrane će koristiti detaljnije razrađene i složene materijale kako bi izdržali više temperature i pritiske pare, kao i toplotne cikluse. Kao takvi, zavareni spojevi različiti metala (DMW) će biti mnogo rasprostranjeniji u novom dizajnu nego ranije i potrebno je da dokažu otpornost na kombinacije oštrih uslova puzanja, korozije / oksidacije i niskocikličnog zamora. DMW između različitih čelika ili legura su podcenjena tema. Iskustveni i dokumentovani preuranjeni nedostaci otkrivaju kritičnost DMW-a.

Ova studija je fokusirana se na DMW između martenzitnih i naprednih austenitnih nerđajućih čelika. Dva kolaborativna projekta vezana su za dostavljene podatke za $18 \% \mathrm{Cr}$ i $25 \% \mathrm{Cr}$ austenitne, otporne na puzanje nerđajuće čelike o karakterizaciji osnovnih metala i zavarivljivosti pri istorodnom $\mathrm{i}$ raznorodnom zavarivanju. Posebne karakteristike raznorodnog zavarivanja se dalje detaljnije analiziraju. Dve glavne metodologije, tj. tehnike direktnog zavarivanja i puterovanja, korišćenjem različitih dodatnih materijala su istraživane i okarakterisane putem uniaksijalnog ispitivanja loma pri puzanju i metalografskog ispitivanja, sa naročitim fokusom na formiranje $i$ morfologiju karbida na liniji stapanja.

Za ograničeno vreme izlaganja od 10kh u ovom projektu, rezultati pokazuju da se javljaju linijske i 
type I carbide formation is occurring when A617 type filler metals are used. The selection of P87 or A82 type filler metals demonstrated isolated to partly aligned carbides respectively at the fusion line. Due to a risk for corrosion and the somewhat better creep rupture strengths at comparable conditions, buttering techniques seem to be recommended above direct welding.

\section{Introduction}

State-of-the-art for fossil-fired UltraSuperCritical Power Plants (USC PP) with efficiencies close to $50 \%$, is the $600{ }^{\circ} \mathrm{C}$ technology using steam parameters up to $620{ }^{\circ} \mathrm{C}$ and 300 bar. The main driving force for these developments is the reduction of $\mathrm{CO}_{2}$ emission via increased efficiency and potential co-combustion. It must be noted that the increase in steam temperature is thereby not limited to USC PP but is also applied in advanced Heat Recovery Steam Generators (HRSG's), Generation IV Nuclear Power Plants (NPP) and Concentrated Solar Power (CSP) concepts. It is clear that new advanced materials had to be developed to cope with the extreme steam conditions. Today's market driven power plants need high levels of availability, reliability and flexibility.

Hence materials must outperform in severe conditions and it becomes obvious that low alloys are superseded by more elaborated and complex alloys.

Superheater/reheater systems in USC PP are designed for temperatures far above $600^{\circ} \mathrm{C}$, requiring high creep rupture strength, resistance to low cycle fatigue and to corrosion/oxidation. The current design temperatures of $650{ }^{\circ} \mathrm{C}$ are above the maximum allowable operating temperatures for martensitic steels and, as a consequence, stainless steel or nickel base alloys have to be used. Advanced austenitic stainless steels such as X10CrNiCuNb18-9-3 (Super304HCu/DMV304HCu) and $\mathrm{X} 6 \mathrm{CrNiNbN25-20}$ (HR3C/DMV310N) have been developed to fulfil this role [1][2][3].

The selection of these advanced austenitic stainless steels provokes a specific need to address the issue of Dissimilar Metal Welding (DMW) because modern $600{ }^{\circ} \mathrm{C}$ power plants also use components made from low alloys and martensitic steels. As such, connections in the boiler where martensitic steels have to be welded to austenitic stainless steels are numerous (Table 1). The design and location of these DMWs also need a specific approach particularly to address avoidance of critical areas of high stress. povezane formacije karbida tipa I pri korišćenju materijala tipa A617. Izbor dodatnog materijala tipa P87 ili A82 je pokazao izolovane delimično poravnate karbide na liniji stapanja. Zbog rizika od korozije i nešto bolje granice puzanja do loma u uporedivim uslovima, izgleda da su preporučene tehnike puterovanja iznad direktnog zavarivanja.

\section{Uvod}

Poslednja reč tehnologije ultra-super-kritičnih enrgetskih postrojenja (USC PP) na fosilna goriva, sa efikasnošču blizu $50 \%$, je $600{ }^{\circ} \mathrm{C}$ tehnologija koja koristi paru sa parametrima do $620^{\circ} \mathrm{C}$ i 300 bar. Glavna pokretačka snaga za ovaj razvoj je smanjenje emisije $\mathrm{CO}_{2}$ kroz povećanu efikasnost i potencijalno zajedničko sagorevanje. Potrebno je napomenuti da povećanje temperature pare nije ograničeno na USC PP, već se takođe primjenjuje u naprednim generatorima pare za oporavak toplote (HRSG), generaciji IV nuklearnih elektrana (NPP) i koncepciji koncentrisane solarne energije (CSP). Jasno je da je potrebno razviti nove napredne materijale kako bi se suočili sa ekstremnim uslovima pare. Današnje elektrane na tržištu zahtevaju visok stepen dostupnosti, pouzdanosti i fleksibilnosti.

Zbog toga materijali moraju da nadvladaju teške uslove i postaje očigledno da su niskolegirani materijali zamenjeni razvijenijim i kompleksnijim legurama.

Sistemi superzagrejača / ponovnih zagrejača u USC PP su projektovani za temperature daleko iznad $600{ }^{\circ} \mathrm{C}$, što zahteva visoku granicu puzanja do loma, otpornost na niskociklični zamor i na koroziju / oksidaciju. Sadašnje projektne temperature od $650{ }^{\circ} \mathrm{C}$ su iznad maksimalno dozvoljenih radnih temperatura za martenzitne čelike i, kao posledica, moraju se koristiti nerđajući čelici ili nikl. Napredni austenitni nerđajući čelici kao što su X10CrNiCuNb18-9-3 (Super304HCu / DMV304HCu) i X6CrNiNbN25-20 (HR3C / DMV310N) su razvijeni da bi ispunili ovu ulogu [1] [2] [3].

Izbor ovih naprednih austenitnih nerđajućih čelika izaziva specifičnu potrebu za rešavanjem problema zavarivanja raznorodnih materijala (DMV), jer savremene elektrane od $600{ }^{\circ} \mathrm{C}$ takođe koriste komponente napravljene od niskolegiranih i martenzitnih čelika. Tako su, priključci na kotlu u kojima moraju biti zavareni martenzitni čelici i austenitni nerđajući čelici brojni (tabela 1). Dizajn i lokacija ovih DMV-a takođe traži poseban pristup posebno za rešavanje izbegavanja kritičnih područja sa visokim naprezanjima. 


\begin{tabular}{|l|l|c|}
\hline \multicolumn{2}{|l|}{ DMWs Martensitic/Austenitic } & \\
\hline Component & DMW & number \\
\hline SH2 In & T91/Super304H & 780 \\
\hline SH2 Out & T92/Super304H & 780 \\
\hline SH3 In & T92/Super304H & 570 \\
\hline SH3 Out & F92/A617/Super304H & 1140 \\
\hline RH2 In & T92/Super304H & 702 \\
\hline RH2 Out & F92/A617/HR3C & 702 \\
\hline & & 4674 \\
\hline
\end{tabular}

Table 1: Number of DMWs in $600^{\circ} \mathrm{C}$ USC PP (typical)

Tabela 1: Broj DMW na $600^{\circ} \mathrm{C}$ USC PP (tipično)

The welding of dissimilar metals however is always a challenge. Differences in mechanical/physical properties, creep rupture strength and oxidation/corrosion resistance as well as microstructural instabilities need to be considered. Especially in the case of martensitic/austenitic DMWs, the difference in thermal expansion and carbon migration effects caused by the strongly differing $\mathrm{Cr}$-contents, determine the life expectancy of the DMWs. Cycling resulting from a market driven demand for energy, may cause these welds to be susceptible to thermo-mechanical fatigue cracking mechanisms [4].

There are a number of practical solutions for welding martensitic/austenitic DMWs. Connections can be made by direct welding using Ni-based filler metals (e.g. Incoweld A/A82/A182/A617) or specially designed $9 \% \mathrm{Cr}$ filler metals (EPRI P87) and including a Post Weld Heat Treatment (PWHT). As an alternative, martensitic components can be buttered first using Ni-based filler metals (e.g. e.g. Incoweld A/A82/A182/A617) or P87, PWHT'ed and than welded to the austenitic component without further PWHT. After buttering, a PWHT is applied either as a tempering or as a full normalizing and tempering heat treatment. Otherwise transition pieces in Ni-alloys (e.g. A617) can be used avoiding a martensitic/austenitic stainless steel DMW. Finally, flanged connections are considered where possible but require an indepth approach concerning material selection for bolts and gaskets in such a high pressure/temperature application.

$\mathrm{Ni}$-base filler metals are recommended for DMWs for their metallurgical compatibility, intermediate creep rupture strengths and high ductility as well as for their intermediate thermal expansion coefficient. $\mathrm{Ni}$-base filler metals restrict the carbon migration inherent to the Cr-content differences of both components due to the lower solubility and diffusion coefficient [5]. However, a very thin Cr-
Međutim, zavarivanje različitih metala uvek predstavlja izazov. Treba razmotriti razlike u mehaničkim i fizičkim svojstvima, čvrstoću puzanja do loma i otpornosti na oksidaciju / koroziju, kao i mikrostrukturne nestabilnosti. Posebno u slučaju martenzitno/austenitnog DMW-a, razlika u termičkom ekspanziji i efektima migracije ugljenika izazvana snažno različitim sadržajem $\mathrm{Cr}$-a određuje očekivani životni vek DMW-a. Ciklična naprezanja, koja proizilazi iz tržišne potražnje za energijom, mogu dovesti do toga da ti zavareni spojevi budu podložni termo-mehaničkim mehanizmima prslina usled zamora [4].

Postoji niz praktičnih rešenja za zavarivanje martenzitnih / austenitnih DMW. Priključci se mogu izraditi direktnim zavarivanjem dodatnim materijalom na bazi $\mathrm{Ni}$ (npr. Incoweld A / A82 / A182 / A617) ili specijalno dizajniranih $9 \% \mathrm{Cr}$ dodatnih materijala (EPRI P87), uključujući i termičku obradu posle zavarivanja (PWHT). Kao alternativu, martenzitne komponente mogu prvo da se puteruju dodatnim materijalom na bazi $\mathrm{Ni}$ (na primer, Incoweld A / A82 / A182 / A617) ili P87, primeni PWHT i da se zavaruju sa austenitnom komponentom bez dalje PWHT. Nakon puterovanja, PWHT se primenjuje ili kao žarenje ili kao potpuna normalizacija i žarenje. U suprotnom mogu se koristiti prelazni komadi od Ni-legura (npr. A617) izbegavajući martenzitno / austenitni DMW. Najzad, prirubničke veze se razmatraju gde je to moguće, ali zahtevaju detaljan pristup izbora materijala za vijke i navrtke u takvoj aplikaciji visokog pritiska/temperature.

Dodatni materijali na bazi $\mathrm{Ni}$ preporučuju se za DMW zbog njihove metalurške kompatibilnosti, srednje granice puzanja do loma i visoke duktilnosti, kao i za njihovog srednjeg termičkog koeficijenta ekspanzije. Dodatni materijali na bazi $\mathrm{Ni}$ ograničavaju migraciju ugljenika koja je inherentna razlikama sadržaja $\mathrm{Cr}$ sadržaja obe komponente usled manje rastvorljivosti i 
carbide layer (type I) formed at the fusion line of the martensitic component may initiate microvoiding and premature creep failures [6]. Using a Ni-alloy transition piece does not avoid this phenomenon. In this case, a thin carbide layer may form at the martensitic side after PWHT or in service.

In this project the opportunity has been taken to select recently developed P87 (EPRI/Metrode/EuroWeld) $\mathrm{Ni}$ base filler metals [7][8][9]. The main criteria for selecting this filler metal are the closely matching coefficient of thermal expansion and the matching $\mathrm{C} / \mathrm{Cr}$ level related to the $9 \mathrm{Cr}$ steels. This results in a much lower stressed area at the martensitic side of the DMW as well as the potential avoidance of carbon migration and formation of detrimental type I carbides at the interface. Also the fact that P87 contains only low levels of $\mathrm{Al}$ and $\mathrm{Ti}$, compared to e.g. A617, prevents the weld from a precipitation hardening mechanism in service. In view of these advantages, P87 tends to be a promising filler metal for DMWs.

\section{Experimental procedure}

Two collaborative research projects, initiated and managed by the Belgian Welding Institute (BWI) and Engie Lab-Laborelec [10][11], focused on the characterization of the major properties of advanced stainless steel tubes DMV $304 \mathrm{HCu}$, DMV310N and HR3C as well as the assessment of weldability related to similar and dissimilar welding. The mechanical characteristics of the base metals have been determined at room and high temperature using (hot) tensile testing and uni-axial isothermal creep rupture testing. Thermal simulations (single and multicycle) were performed for the weldability assessment followed by reheat cracking and hot ductility testing.

In the above-mentioned research projects two common fabrication processes for DMWs were selected i.e. direct welding and buttering techniques.

Welding procedures were qualified according to the European Standards (EN ISO 15614-1) and welds were characterized using conventional mechanical testing including metallographic examination and uni-axial isothermal crossweld creep rupture testing.

Afterwards, more extensive microscopic (SEM) examination has been performed on specific fusion line (FL) features i.e. carbide formation (type $\mathrm{I} / \mathrm{II}$ ). The fusion koeficijenta difuzije [5]. Međutim, vrlo tanak sloj Crkarbida (tip I) koji se formira na liniji stapanja martenzitne komponente može pokrenuti mikropraznine i preuranjene lomove usled puzanja [6]. Korišćenje prelaznog komada od Ni-legure ne izbegava ovu pojavu. U ovom slučaju, tanki karbidni sloj se može formirati na martenzitnoj strani nakon PWHT ili eksploatacije.

$\mathrm{U}$ ovom projektu iskorišćena je mogućnost odabira nedavno razvijenih P87 (EPRI / Metrode / EuroWeld) dodatnih materijala na bazi $\mathrm{Ni}$ [7] [8] [9]. Glavni kriterijumi za odabir ovog dodatnog materijala je koeficijent toplotnog širenja i odgovarajući C / $\mathrm{Cr}$ nivo koji se odnosi na $9 \mathrm{Cr}$ čelike. Ovo rezultuje znatno nižim naprezanjima oblasti na martenzitnoj strani DMW-a, kao i na potencijalno izbegavanje migracije ugljenika i stvaranje štetnih karbida tipa I na međupovršini. Takođe, činjenica da P87 sadrži samo niske nivoe Al i Ti, u poređenju sa npr. A617, sprečava u šavu nastanak mehanizma taložnog otvrdnjavanja tokom eksploatacije. S obzirom na ove prednosti, P87 ima tendenciju da bude obećavajući dodatni materijla za DMW.

\section{Eksperimentalna procedura}

Dva kolaborativna istraživačka projekta, inicirana i upravljana od strane Belgijskog instituta za zavarivanje (BWI) i Engie Lab-Laborelec [10] [11], fokusirali su se na karakterizaciju glavnih osobina naprednih cevi od nerđajućeg čelika DMV304HCu, DMV310N i HR3C, kao i ocenu zavarljivosti koja se odnosi na istorodno i raznorodno zavarivanje. Mehaničke karakteristike osnovnih metala određene su na sobnoj i visokoj temperaturi (vruće) ispitivanjem zatezanjem $\mathrm{i}$ ispitivanje jednoosnim izotermalnim puzanjem do loma. Toplotne simulacije (jednociklične i multiciklične) izvedene su za procenu zavarljivosti preko pojave prslina usled ponovnog zagrevanja $i$ ispitivanjem duktilnosti na toplo.

$U$ gore pomenutim istraživačkim projektima izabrana su dva uobičajena procesa za DMW, tj. tehnike direktnog zavarivanja i puterovanja.

Procedure zavarivanja su kvalifikovane prema evropskim standardima (EN ISO 15614-1) i karakteristični zavareni spojevi korišćenjem konvencionalnih mehaničkih ispitivanja, uključujući metalografski pregled i ispitivanje jednosnim izotermalnim puzanjem do loma poprečnog preseka.

Nakon toga, izvršen je obimniji mikroskopski (SEM) pregled na određenoj liniji stapanja (FL) karakteristika tj. stvaranje karbida (tip I / II). Ispitivanje linije stapanja vezano za karbidnu 
line investigation related to carbide morphologies and type is performed using SEM/EDS JEOL JSM6490LV equipment and Oxford Inca software.

The chemical composition of the advanced austenitic stainless steel tubes is given in Table 2 and 3. The chemical composition of the Grade 92 tube is given in Table 4.

\begin{tabular}{|c|c|c|c|c|c|c|c|c|c|c|} 
& $\mathrm{C}$ & $\mathrm{Si}$ & $\mathrm{Mn}$ & $\mathrm{N}$ & $\mathrm{Cr}$ & $\mathrm{Cu}$ & $\mathrm{Nb}$ & $\mathrm{Ni}$ & $\mathrm{B}$ & $\mathrm{Al}$ \\
\hline Min. & 0.070 & $\mathrm{na}$ & $\mathrm{na}$ & 0.0500 & 17.000 & 2.500 & 0.300 & 7.500 & 0.0010 & 0.003 \\
\hline Max. & 0.130 & 0.3000 & 1.00 & 0.1200 & 19.000 & 3.500 & 0.600 & 10.500 & 0.0100 & 0.030 \\
\hline Heat 351180 & 0.092 & 0.2500 & 0.65 & 0.1050 & 18.220 & 3.010 & 0.450 & 8.860 & 0.0032 & 0.010 \\
\hline
\end{tabular}

Table 2: Base metal DMV304HCu - Chemical analysis (weight \%)

Tabela 2: Osnovni materijal DMV304Hcu- Hemijska analiza (tež. \%)

\begin{tabular}{|c|c|c|c|c|c|c|c|c|}
\hline & $\mathrm{C}$ & $\mathrm{Si}$ & $\mathrm{Mn}$ & $\mathrm{Cr}$ & $\mathrm{Ni}$ & $\mathrm{Nb}$ & $\mathrm{N}$ & $\mathrm{B}$ \\
\hline Min. & ns & $\mathrm{ns}$ & $\mathrm{ns}$ & 22,8 & 16,85 & 0,15 & 0,14 & $\mathrm{~ns}$ \\
\hline Max. & 0,11 & 1,55 & 2,04 & 27,2 & 23,20 & 0,65 & 0,36 & $\mathrm{~ns}$ \\
\hline Heat F04154 & 0,05 & 0,35 & 1,21 & 24,3 & 20,7 & 0,46 & 0,22 & 0,0015 \\
\hline Heat F226013 & 0,05 & 0,38 & 1,20 & 24,5 & 20,3 & 0,47 & 0,28 & 0,0012 \\
\hline
\end{tabular}

Table 3: Base metal DMV310N/HR3C - Chemical analysis (weight \%)

Tabela 3: Osnovni materijal DMV310N/HR3C- Hemijska analiza (tež. \%)

\begin{tabular}{|c|c|c|c|c|c|c|c|c|c|c|c|c|}
\hline & $\mathrm{C}$ & $\mathrm{Si}$ & $\mathrm{Mn}$ & $\mathrm{Cr}$ & $\mathrm{N}$ & $\mathrm{Mo}$ & $\mathrm{Ni}$ & $\mathrm{Al}$ & $\mathrm{Nb}$ & $\mathrm{V}$ & $\mathrm{B}$ & $\mathrm{W}$ \\
\hline Min. & 0.07 & $\mathrm{na}$ & 0.30 & 8.50 & 0.030 & 0.30 & $\mathrm{na}$ & $\mathrm{na}$ & 0.04 & 0.15 & 0.001 & 1.50 \\
Max. & 0.13 & 0.50 & 0.60 & 9.50 & 0.070 & 0.60 & 0.40 & 0.040 & 0.09 & 0.25 & 0.006 & 2.00 \\
\hline Heat SS40890 & 0.12 & 0.20 & 0.50 & 8.79 & 0.047 & 0.38 & 0.15 & 0.012 & 0.06 & 0.20 & 0.003 & 1.67 \\
\hline Heat SS973521 & 0.11 & 0.19 & 0.47 & 8.59 & 0.048 & 0.42 & 0.19 & 0.013 & $\mathrm{~ns}$ & 0.19 & 0.003 & 1.67 \\
\hline
\end{tabular}

Table 4: Base metal A213T92 - Chemical analysis (weight \%)

Tabela 4: Osnovni materijal A213T92 - Hemijska analiza (tež. \%)

All test welds have been realized by a manual GTAW welding process. Three type of filler metals i.e. A617, A82 and P87 were selected and their chemical analysis is given in Table 5.
Svi testovi zavarivanja realizovani su ručnim TIG postupkom zavarivanja. Izabrane su tri vrste dodatnih materijala tj. A617, A82 i P87, a njihova hemijska analiza je data u Tabeli 5 .

\begin{tabular}{|l|c|c|c|c|c|c|c|c|c|c|c|}
\hline $\begin{array}{l}\text { AWS classification } \\
\text { or trade name }\end{array}$ & $\mathrm{C}$ & $\mathrm{Si}$ & $\mathrm{Mn}$ & $\mathrm{Ni}$ & $\mathrm{Cr}$ & $\mathrm{Mo}$ & $\mathrm{Nb}$ & $\mathrm{Co}$ & $\mathrm{Al}$ & $\mathrm{Ti}$ & $\mathrm{Fe}$ \\
\hline ERNiCrCoMo-1 (A617) & 0,057 & 0,09 & 0,05 & 55,60 & 22,03 & 8,70 & $\mathrm{~ns}$ & 10,83 & 1,250 & 0,31 & 0,68 \\
\hline ERNiCr-3(A82) & 0,02 & 0,1 & 3,0 & $>67,0$ & 20,00 & $\mathrm{~ns}$ & 2,5 & $\mathrm{~ns}$ & $\mathrm{~ns}$ & $\mathrm{~ns}$ & $<2$ \\
\hline P87 & 0,1 & 0,3 & 1,5 & bal & 9 & 2 & 1 & $\mathrm{~ns}$ & $\mathrm{~ns}$ & $\mathrm{~ns}$ & 38 \\
\hline
\end{tabular}

Table 5: Filler metal types - Chemical analysis (weight \%)

Tabela 5: Dodatni materijal - Hemijska analiza (tež. \%)

Two types of heat treatment have been applied. A tempering treatment (PWHT) at $740^{\circ}-760^{\circ} \mathrm{C}$ for 30 minutes and a re-normalizing and tempering heat treatment at $1060{ }^{\circ} \mathrm{C} / 20 \mathrm{~min}$. and $780{ }^{\circ} \mathrm{C} / 60 \mathrm{~min}$. respectively.

Uni-axial isothermal crossweld creep rupture testing has been conducted for direct welding at $625^{\circ} \mathrm{C}$ and stress levels of 160, 140, 105 and 80 $\mathrm{MPa}$. For buttering techniques, uni-axial isothermal crossweld creep rupture testing has been conducted at $625^{\circ} \mathrm{C}$ and stress levels of 155,138 , 119 and $80 \mathrm{MPa}$. First creep rupture tests have been run at a stress level of $160 \mathrm{MPa}$ or $155 \mathrm{MPa}$ and later changed to $140 \mathrm{MPa}$ or $138 \mathrm{MPa}$
Primenjene su dve vrste toplotne obrade. Obrada žarenjem (PWHT) na $740^{\circ}-760^{\circ} \mathrm{C}$ tokom 30 minuta i re-normalizacija i žarenje na $1060^{\circ} \mathrm{C} / 20 \mathrm{~min}$. i 780 ${ }^{\circ} \mathrm{C} / 60 \mathrm{~min}$.

Jednoosno izotermalno ispitivanje puzanja do loma poprečnog preseka je sprovedeno za direktno zavarivanje na $625^{\circ} \mathrm{C}$ i nivoa naprezanja 160, 140, 105 i $80 \mathrm{MPa}$. Za tehnike puterovanja, ovo ispitivanje je obavljeno na $625{ }^{\circ} \mathrm{C}$ sa nivoom napona 155, 138, 119 i $80 \mathrm{MPa}$. Prvo su ispitivanja puzanja počinjala na nivou napona od $160 \mathrm{MPa}$ ili $155 \mathrm{MPa}$ i kasnije promenjena u $140 \mathrm{MPa}$ ili 138 $\mathrm{MPa}$, iz razloga objašnjenih u ovom radu (vidi stav 
3.1 i respectively for reasons explained further in this paper (see par. 3.1 and 3.2). Creep rupture tests have been performed on EHS and ATS creep machines. The specimen are uni-axially loaded by deadweight or a cantilever deadweight and heated by a three zone furnace. Specimen temperature is measured by thermocouples type $\mathrm{N}$ and $\mathrm{S}$. Creep strains are measured using continuous strain monitoring or after final rupture.

\section{Results}

\subsection{Direct welding}

The DMW Grade 91/92 to advanced austenitic stainless steels by direct welding is of particular interest. It is the most applied type of DMW in the $600^{\circ} \mathrm{C}$ USC concept.

Creep rupture testing provided by the BWI and Engie Lab-Laborelec project, shows the resulting creep strengths (see Table 6). Selecting the appropriate stress levels for target durations of $10 \mathrm{kh}$ presented some difficulty as no relevant data were available in open literature. As a result, stress levels had to be adapted during the course of testing and consequently part of the results are not fully interchangeable.
3.2.). Ispitiovanja puzanja do loma obavljena su na EHS i ATS mašini za puzanje. Uzorak je jednoosno opterećen ukupnom nosivošću ili nosivošću konzolnog nosača i zagrejan sa tri zone peći. Temperatura uzorka meri se termoelementima tipa $\mathrm{N}$ i S. Deformacije pri puzanju se mere kontinuiranim praćenjem senzora ili nakon loma na kraju.

\section{Rezultati \\ 3.1. Direktno zavarivanje}

Posebno je interesenantna DMW klasa 91/92 za napredne austenitne nerđajuće čelike direktnim zavarivanjem. To je najčešće primenjen tip DMW kod $600^{\circ} \mathrm{C}$ USC koncepta.

Testiranje puzanja do loma obezbeđeno projektom BWI i Engie Lab-Laborelec, pokazuje rezultujuće granice puzanja (vidi Tabelu 6). Izbor odgovarajućih nivoa napona za ciljeve trajanja od $10 \mathrm{kh}$ predstavljalo je određene poteškoće u nedostatku relevantnih podataka $u$ otvorenoj literaturi. Kao rezultat toga, nivoi napona morali su biti prilagođeni tokom ispitivanja i samim tim, deo rezultata nije u potpunosti zamenljiv.

\begin{tabular}{|l|l|c|c|c|c|}
\hline $\begin{array}{l}\text { Dissimilar welds } \\
\text { Direct welding }\end{array}$ & \multicolumn{1}{|c|}{$\begin{array}{c}\text { Filler metal } \\
\text { Heat treatment }\end{array}$} & $\begin{array}{c}\text { Temperature } \\
{ }^{\circ} \mathrm{C}\end{array}$ & $\begin{array}{c}\text { Stress } \\
\mathrm{MPa}\end{array}$ & $\begin{array}{c}\text { Rupture } \\
\text { time } \\
\mathrm{h}\end{array}$ & $\begin{array}{c}\text { Fracture } \\
\text { location }\end{array}$ \\
\hline DMV304HCu/T92 & ERNiCrCoMo-1/A617 & 625 & 160 & 101 & T92 BM \\
\cline { 2 - 6 } & tempered & 625 & 140 & 566 & T92 HAZ \\
\cline { 2 - 6 } & P87 & 625 & 105 & 2319 & T92 FL \\
\hline & tempered & 625 & 160 & 101 & $\mathrm{BM} / \mathrm{SCHAZ}$ \\
\hline & & 625 & 140 & 708 & T92 HAZ \\
\hline HR3C/T92 & P87 & 625 & 105 & 2820 & T92 HAZ \\
\hline & tempered & 625 & 105 & 3045 & T92 HAZ \\
\hline & & 625 & 80 & 5329 & T92 FGHAZ \\
\hline DMV310N/T92 & ERNiCr-3/A82 & 625 & 140 & 792 & T92 HAZ \\
\hline & tempered & 625 & 105 & 3005 & T92 HAZ \\
\hline & & 625 & 80 & 7311 & T92 FGHAZ \\
\hline
\end{tabular}

Table 6: Creep rupture testing results of direct welding

Tabela 6. Rezultati ispitivanja puzanja do loma pri direktnom zavarivanju

A617 filler metal shows a characteristic FL fracture location (Figure 1) at the stress level of $105 \mathrm{MPa}$ where P87 filler metal presents a typical expected type IV fracture (Figure 2) in the T92 HAZ being the weakest area of the compound. As such the advantages regarding P87 claimed by EPRI [7][8][9] seem to correlate with the current results.
A617 dodatni materijal pokazuje karakterističnu lokaciju preloma FL (slika 1) na nivou naprezanja od $105 \mathrm{MPa}$ dok P87 dodatni materijal pokazuje tipični očekivani tip loma IV (slika 2) u T92 ZUT koja je najslabija oblast spoja. Tako da su prednosti koje se tiču P87 koje tvrdi EPRI [7] [8] [9] u korelaciji sa trenutnim rezultatima. 


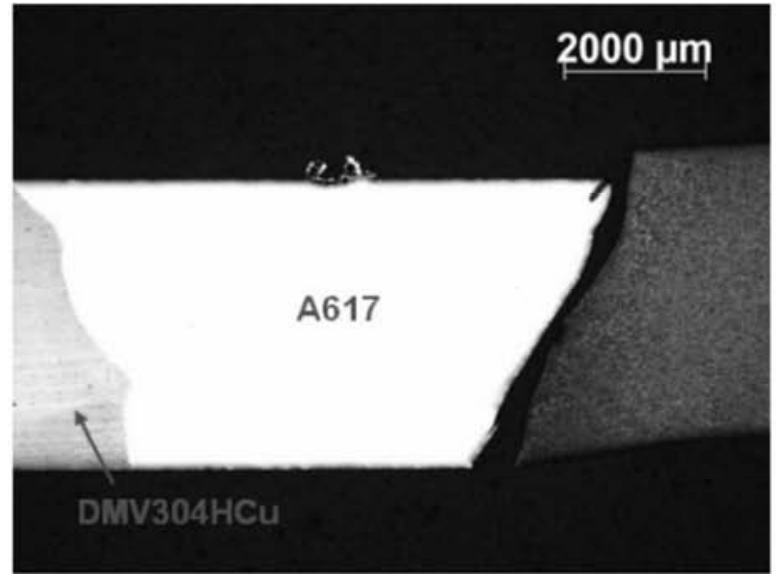

Figure 1: DMV304HCu/T92-A617(105MPa/625 $\mathrm{C})$

Slika 1: DMV304HCu/T92-A617(105MPa/625 $\mathrm{C})$

Based upon the creep test results of direct welding (See Table 6), filler metal P87 is recommended compared to A617 both from the standpoint of creep strength and fracture location. In the DMV310N/HR3C creep testing program regarding direct welding (See Table 6/Figure 3), comparable results at $625^{\circ} \mathrm{C} / 105 \mathrm{MPa}$ regarding creep strength and fracture location were observed for A82 and P87 filler metals. At the stress level of $80 \mathrm{MPa}$ there is a substantial difference between the rupture times of P87 and A82 (5329 vs $7311 \mathrm{~h}$ ).

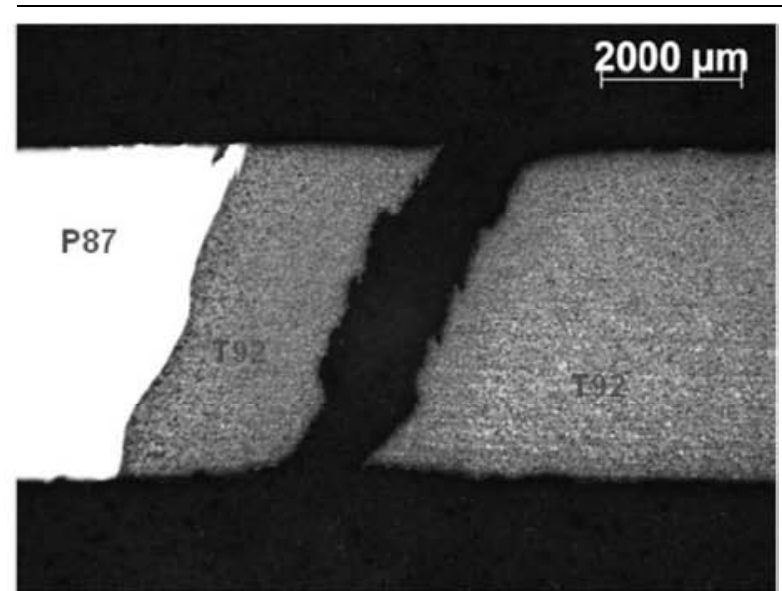

Figure 2: $D M V 304 \mathrm{HCu} / \mathrm{T92}-\mathrm{P} 87\left(105 \mathrm{MPa} / 625^{\circ} \mathrm{C}\right)$

Slika 2: DMV304HCu/T92-P87(105MPa/ $\left.625^{\circ} \mathrm{C}\right)$

$\mathrm{Na}$ osnovu rezultata ispitivanja puzanja kod direktnog zavarivanja (videti tabelu 6) preporučuje se dodatni materijal P87 u poređenju sa A617 sa stanovišta jačine puzanja i lokacije preloma. Kod DMV310N / HR3C programa ispitivanja zamora koji se odnosi na direktno zavarivanje (vidi tabelu 6 / Slika 3), uporedivi rezultati na $625{ }^{\circ} \mathrm{C} / 105 \mathrm{MPa} u$ odnosu na jačinu puzanja i položaj loma su primećeni za A82 i P87 dodatne materijale. Na nivou napona od $80 \mathrm{MPa}$ postoji značajna razlika između vremena do loma P87 i A82 (5329 nasuprot 7311h).

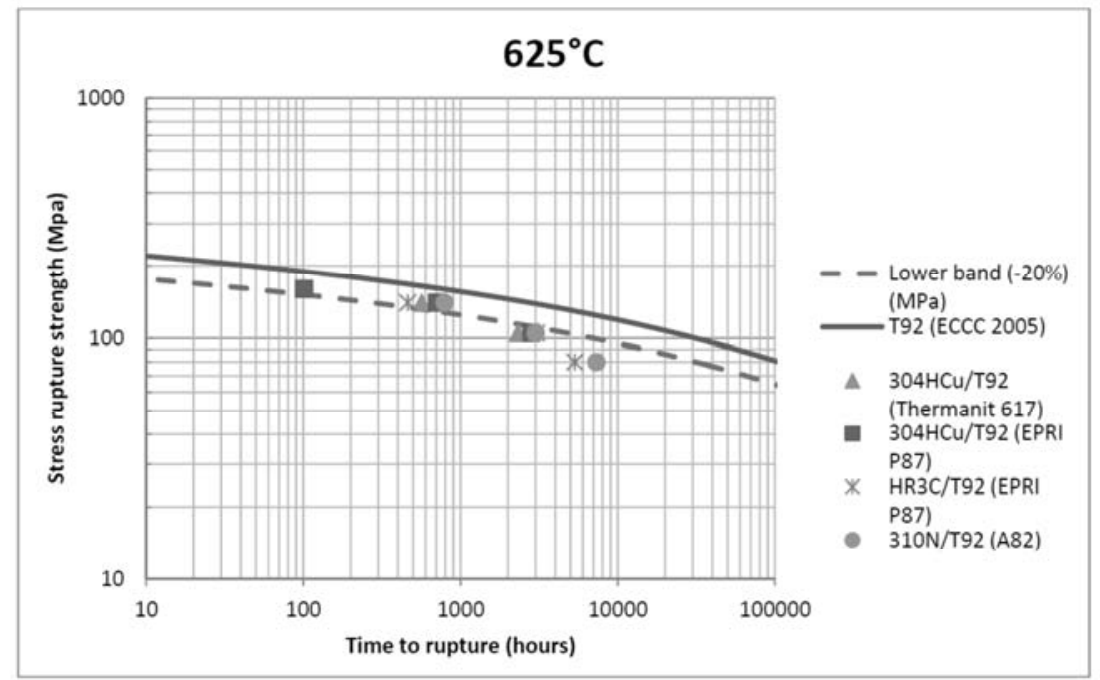

Figure 3: Creep rupture testing results DMW 304HCu/T92, HR3C/T92 and 310N/T92 (direct welding)

Slika 3. Rezultati ispitivanja puzanja do loma DMW 304HCu/T92, HR3C/T92 i 310N/T92 (direktno zavarivanje)

\subsection{Buttering techniques}

In the research projects, buttering technique is applied only on DMV304HCu by selecting 2 filler metals i.e. A617 and P87. After buttering, a heat treatment (PWHT) was performed either by conventional tempering or renormalisation \& tempering. Creep rupture testing at $625{ }^{\circ} \mathrm{C}$ (see Table 7/Figure 5) was initially conducted at three stress levels: 155, 138 and $119 \mathrm{MPa}$.

\subsection{Tehnike puterovanja}

$\mathrm{U}$ istraživačkim projektima, tehnika puterovanja primenjuje se samo na DMV304HCu odabirom 2 dodatna materijala tj. A617 i P87. Nakon puterovanja, obavljena je termička obrada (PHT) ili konvencionalnim žarenjem ili renormalizacijom i žarenjem. Ispitivanje puzanja do loma na $625{ }^{\circ} \mathrm{C}$ (vidi tabelu 7 / Slika 5) u početku je sprovedeno na tri nivoa napona: 155, 138 i $119 \mathrm{MPa}$. 


\begin{tabular}{|l|l|c|c|c|c|}
\hline $\begin{array}{l}\text { Dissimilar welds } \\
\text { Buttering technique }\end{array}$ & $\begin{array}{c}\text { Filler metal } \\
\text { Heat treatment } \\
\text { Final weld }\end{array}$ & $\begin{array}{c}\text { Temperature } \\
{ }^{\circ} \mathrm{C}\end{array}$ & $\begin{array}{c}\text { Stress } \\
\mathrm{MPa}\end{array}$ & $\begin{array}{c}\text { Rupture } \\
\text { time } \\
\mathrm{h}\end{array}$ & $\begin{array}{c}\text { Fracture } \\
\text { location }\end{array}$ \\
\hline DMV304HCu/T92 & $\begin{array}{l}\text { Buttered A617 } \\
\text { tempered }\end{array}$ & 625 & 155 & 152 & T92 BM \\
\cline { 2 - 6 } & Thermanit 304HCu & 625 & 138 & 948 & T92 ICHAZ \\
\cline { 2 - 6 } & Buttered P87 & 625 & 119 & 1790 & T92 FL \\
\hline & tempered & 625 & 119 & 1251 & T92 FGHAZ \\
\hline & P87 (AW) & 625 & 80 & 7654 & T92 FGHAZ \\
\cline { 2 - 6 } & Buttered P87 & 625 & 138 & 370 & T92 FL \\
\hline & Norm \& temp & 625 & 119 & 1184 & T92 FL \\
\hline & P87 (AW) & 625 & 80 & 8457 & T92 FL \\
\hline
\end{tabular}

Table 7: Creep rupture testing results of buttering techniques

Tabela 7. Rezultati ispitivanja puzanja do loma kod tehnike puterovanja

Due to lacking published data in open literature for these specific DMWs, it was experienced during the course of the project, that the stress level of 119 $\mathrm{MPa}$ was too high to give creep rupture at an estimated rupture time of about 10kh. Therefore, the stress level for the other planned creep tests (10kh) was reduced to $80 \mathrm{MPa}$. The forced change in stress level however makes it more difficult to compare test results to each other as also an effect on the fracture location is expected.

The buttered A617 DMW was not tested at $80 \mathrm{MPa}$ due to reasons explained and as such cannot be compared.

At comparable creep testing conditions (80 $\mathrm{MPa} / 625{ }^{\circ} \mathrm{C}$ and $>3000 \mathrm{~h}$ ) for direct welding and buttering techniques, it can be stated that P87 buttered welds demonstrate higher creep strength both in the tempered and renormalized \& tempered condition. The relatively large difference in rupture times between $7654 \mathrm{~h}$ (buttered \& tempered) and $5329 \mathrm{~h}$ (direct welding \& tempered) might be influenced by small differences in chemical composition and heat treatment of the T92 tubes used and/or the somewhat higher selected holding temperature during PWHT $\left(760{ }^{\circ} \mathrm{C}\right.$ i.s.o. $\left.740{ }^{\circ} \mathrm{C}\right)$ after buttering. Slightly better results $(8457 \mathrm{~h})$ were obtained for the re-normalized \& tempered condition (Figure 5). The fracture locations were similar for all test cases i.e. T92 (FG) HAZ except for the re-normalized \& tempered condition where fracture occurred in the fusion line (FL) (Figure 4). This can be explained by the effect of the renormalizing \& tempering heat treatment which restores the microstructure at the initial HAZ (T92) and changes fracture location back to the fusion line (FL). The expected fracture location for these type of DMWs however is via type IV cracking. It makes the re-normalizing and tempering heat treatment a less optimal choice.
Zbog nedostatka objavljenih podataka u otvorenoj literaturi za ove specifične DMW, tokom projekta se desilo da je nivo napona $119 \mathrm{MPa}$ previsok da bi se došlo do loma usled puzanja pri procenjenom vremenu od oko 10k. Zbog toga je nivo napona za ostale planirane testove puzanja (10k) smanjen na $80 \mathrm{MPa}$. Prisilna promena nivoa stresa međutim otežava upoređivanje rezultata ispitivanja jednih sa drugima, a takođe se očekuje i efekat na lokaciji preloma.

Puterovani A617 DMW nije testiran na $80 \mathrm{MPa}$ zbog ovog obrazloženja i zbog toga se ne može se upoređivati.

$\mathrm{U}$ uporednim uslovima testiranja $\left(80 \mathrm{MPa} / 625^{\circ} \mathrm{C}\right.$ i> $3000 \mathrm{~h})$ za tehnike direktnog zavarivanja i puterovanja, može se konstatovati da P87 puterovani zavareni elementi pokazuju veću čvrstoću pri puzanju kako u žarenom, tako i u renormalizovanom i otpuštenom stanju. Relativno veliku razliku u vremenu do loma između $7654 \mathrm{~h}$ (puterovano i žareno) i 5329h (direktno zavareno i žareno) mogu uticati male razlike u hemijskom sastavu i toplotnom tretmanu upotrebljenih T92 cevi i/ili nešto viših odabranih temperatura držanja temperatura tokom PVHT $\left(760{ }^{\circ} \mathrm{C}\right.$ i.s. $\left.740{ }^{\circ} \mathrm{C}\right)$ nakon butteringa. Dobijeni su nešto bolji rezultati (8457h) za renormalizovano i žareno stanje (slika 5). Lokacije preloma bile su slične za sve ispitne slučajeve, tj. T92 (FG-fino zrno) ZUT, osim kod renormalizovanog i žarenog stanja gde je došlo do loma na liniji stapanja (FL) (Slika 4). Ovo se može objasniti efektom termičke obrade ponovnog normalizovanja i žarenja koja vraća mikrostrukturu na inicijalnu ZUT (T92) i menja lokaciju preloma nazad na liniju stapanja (FL). Očekivana lokacija preloma za ove vrste DMW međutim je preko prslina tipa IV. To čini renormalizaciju i žarenje manje optimalnim izborom termičke obrade. 


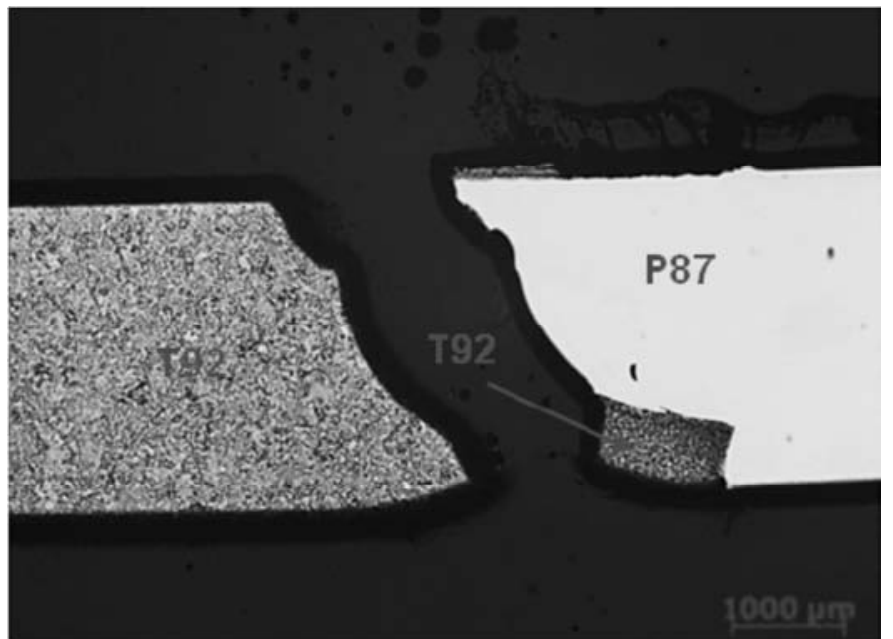

Figure 4: $P 87$ buttered DMW $304 \mathrm{HCu} / \mathrm{T92}$ re-N\&T - 80MPa/ $625^{\circ} \mathrm{C}-8457 \mathrm{~h}$

Slika 4: $P 87$ puterovani DMW $304 \mathrm{HCu} / \mathrm{T9} 2$ re-normalizovan i žaren $-80 \mathrm{MPa} / 625^{\circ} \mathrm{C}-8457 \mathrm{~h}$

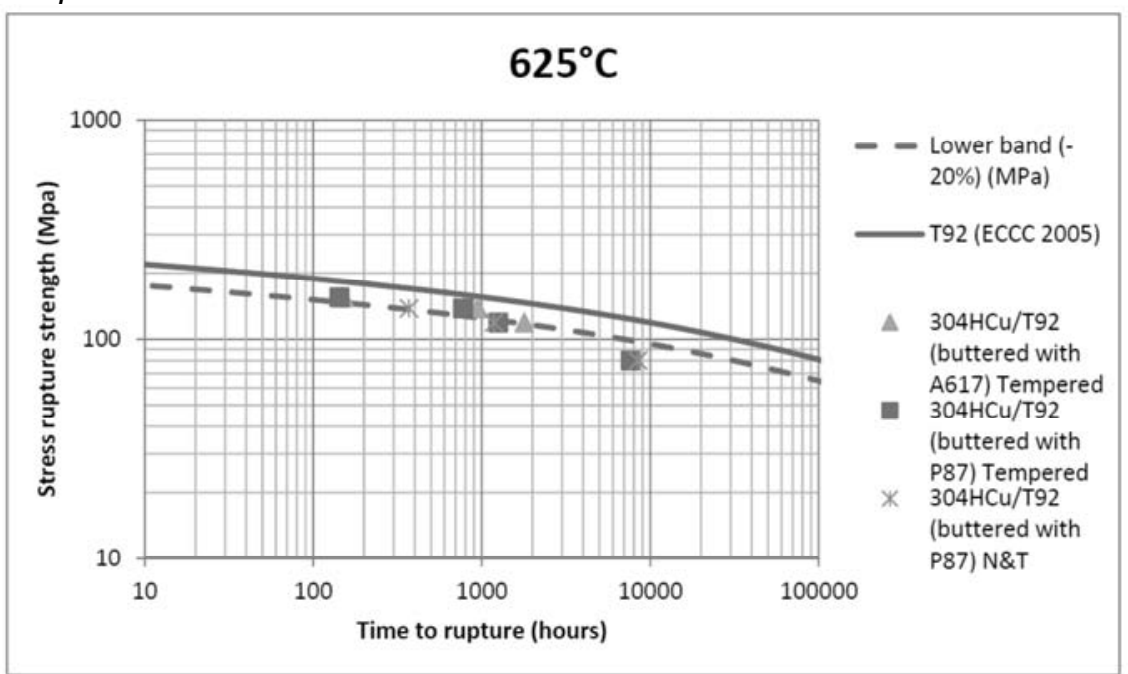

Figure 5: Creep rupture testing results of DMW 304HCu/T92 (buttering)

Slika 5. Rezultati ispitivanja puzanja do loma DMW 304HCu/T92 (puterovan)

\subsection{Fusion line investigation}

The fusion line investigation focussed on carbide formation (type I/II) at the fusion line between T92 and the filler metal type used for welding. Only specimen that were creep rupture tested or thermally aged with times equal or above $3000 \mathrm{~h}$ were investigated. This is due to the required time to form and grow carbides [13] as well as the limited resolution of SEM analysis.

More detailed investigation (SEM) [12] on FL type I carbide formation between A617, A82 and P87 filler metals showed a difference in type I carbide morphologies as can be seen from Figure 6 to 9 . Type II morphology carbides, characterized by a wide band of fine dispersed carbides and beneficial to cracking, have not been observed. This might probably be due to the low heat input welding process which did not allow sufficient dilution during the weld cycle. They are also more typical for DMWs using stainless steel filler metals [13] [18].
3.3 Ispitivanje linije stapanja

Istraživanje linije stapanja fokusiralo se na formiranje karbida (tip I / II) na liniji stapanja između T92 i dodatnog materijala za zavarivanje. Jedini uzorak koji je bio ispitivan na puzanje ili termički staren u trajanju od ili iznad 3000h. Ovo je zbog potrebnog vremena za formiranje i rast karbida [13], kao i ograničeno rezolucija SEM analize.

Detaljnija istraživanja (SEM) [12] o formiranju karbida na liniji stapanja tipa I između metala A617, A82 i P87 pokazuju razliku u morfologijama karbida tipa I, što se vidi iz slika 6 do 9. Karbid tipa II koje karakterišu široke trake fino dispergovanih karbida i pogoduju nastanku prslina, nisu primećeni. Ovo se verovatno moglo dogoditi zbog procesa zavarivanja sa niskim unosom toplote koji nije omogućio dovoljno razblaživanje tokom ciklusa zavarivanja. Oni su takođe tipičniji za DMW-ove koji dodatne materijale na bazi nerđajućeg čelika [13] [18]. 

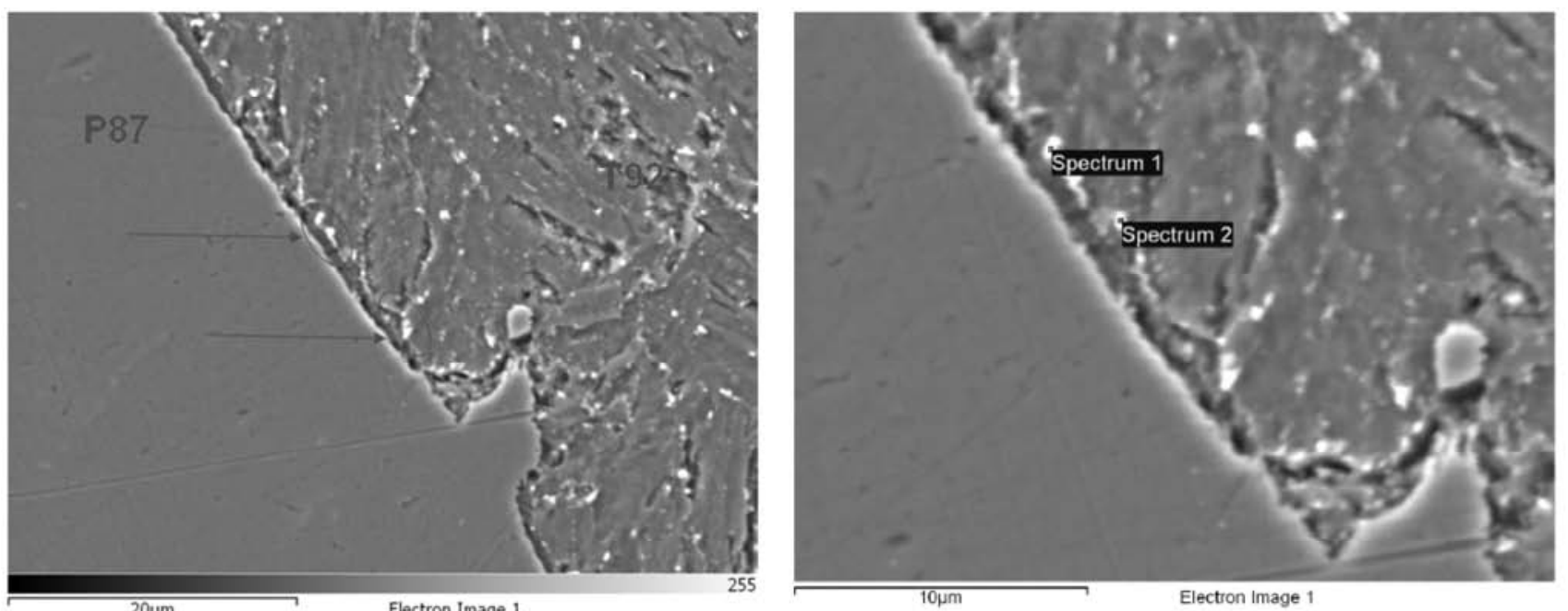

Figure 6: Specimen A -DMV304HCu/T92/P87 filler, thermally aged (3000h)

Slika 6. Epruveta A- DMV304HCu/T92/P87 dodatni materijal, termički staren (3000h)

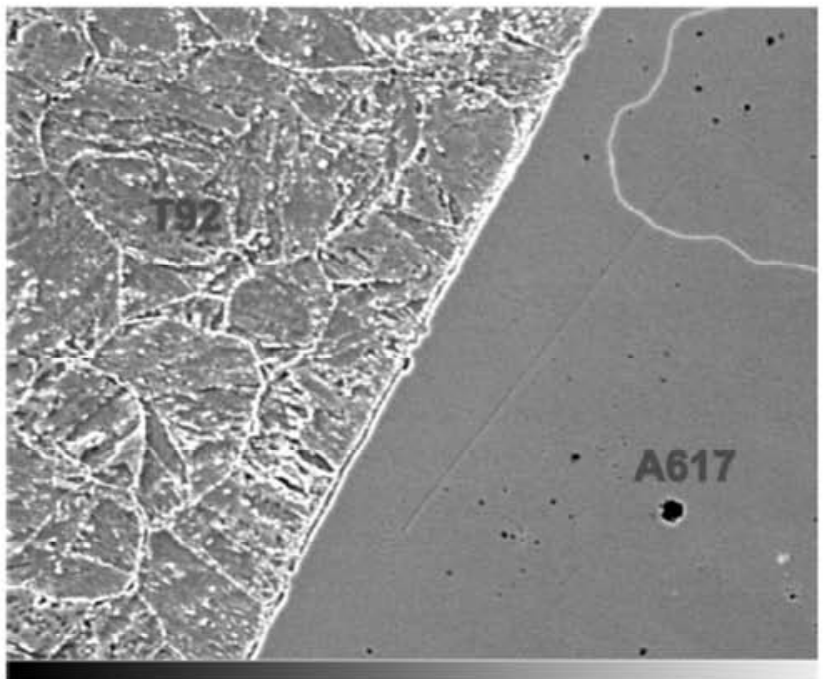

$60 \mu \mathrm{m}$

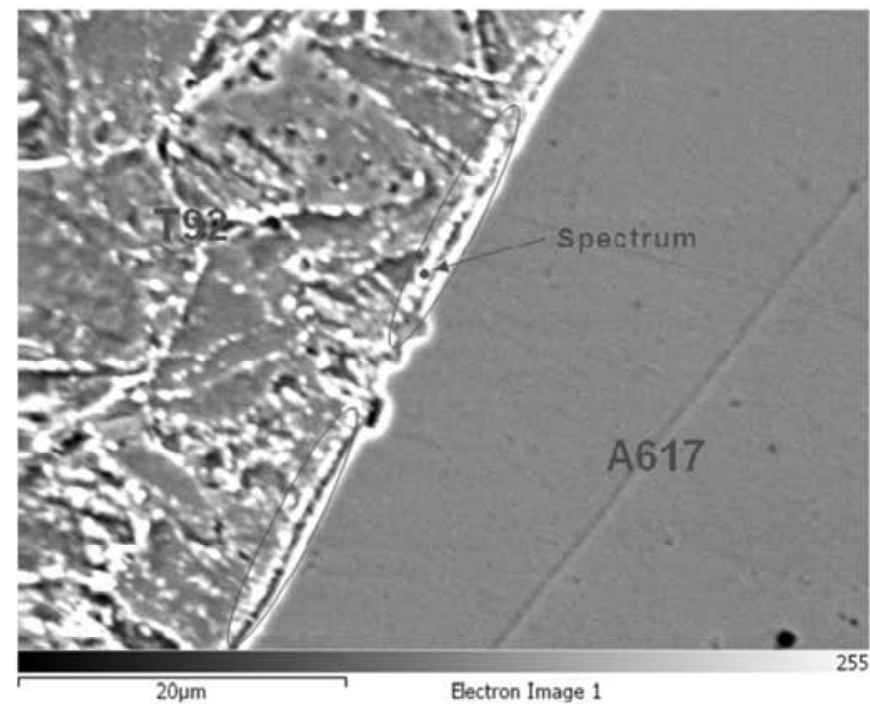

Electron Image 1

Figure 7: Specimen B - DMV304HCu/T92/A617 filler, thermally aged (3000h) Slika 7. Epruveta B- DMV304HCu/T92/A617 dodatni materijal, termički staren (3000h)

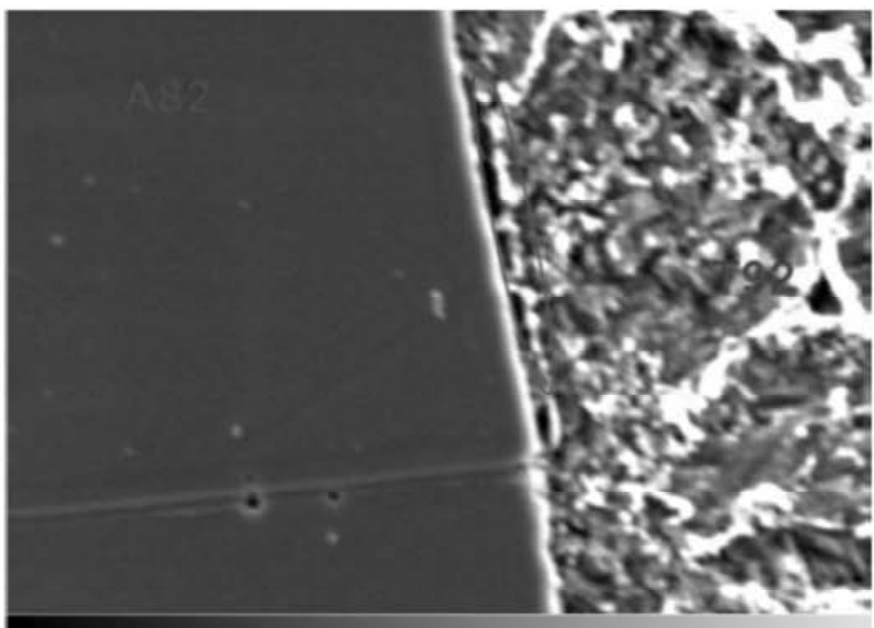

$20 \mu \mathrm{m}$

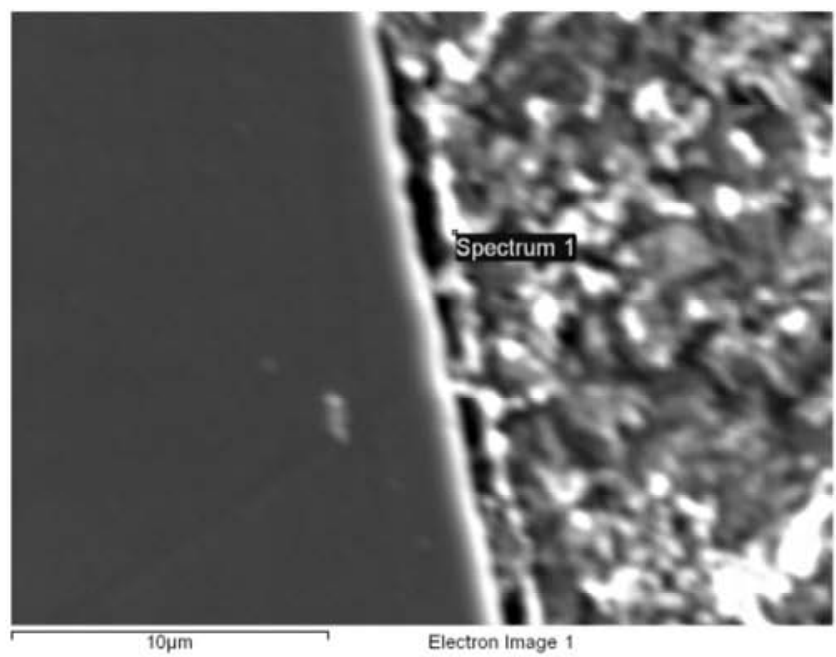

Electron Image 1

Figure 8: Specimen C - DMV310N/T92/A82 filler, direct welding \& tempering (105Mpa $\left.625^{\circ} \mathrm{C} / 3005 \mathrm{~h}\right)$ Slika 8. Epruveta C- DMV310N/T92/A82 dodatni materijal, direktno zavaren i žaren (105Mpa $625^{\circ} \mathrm{C} / 3005 \mathrm{~h}$ ) 

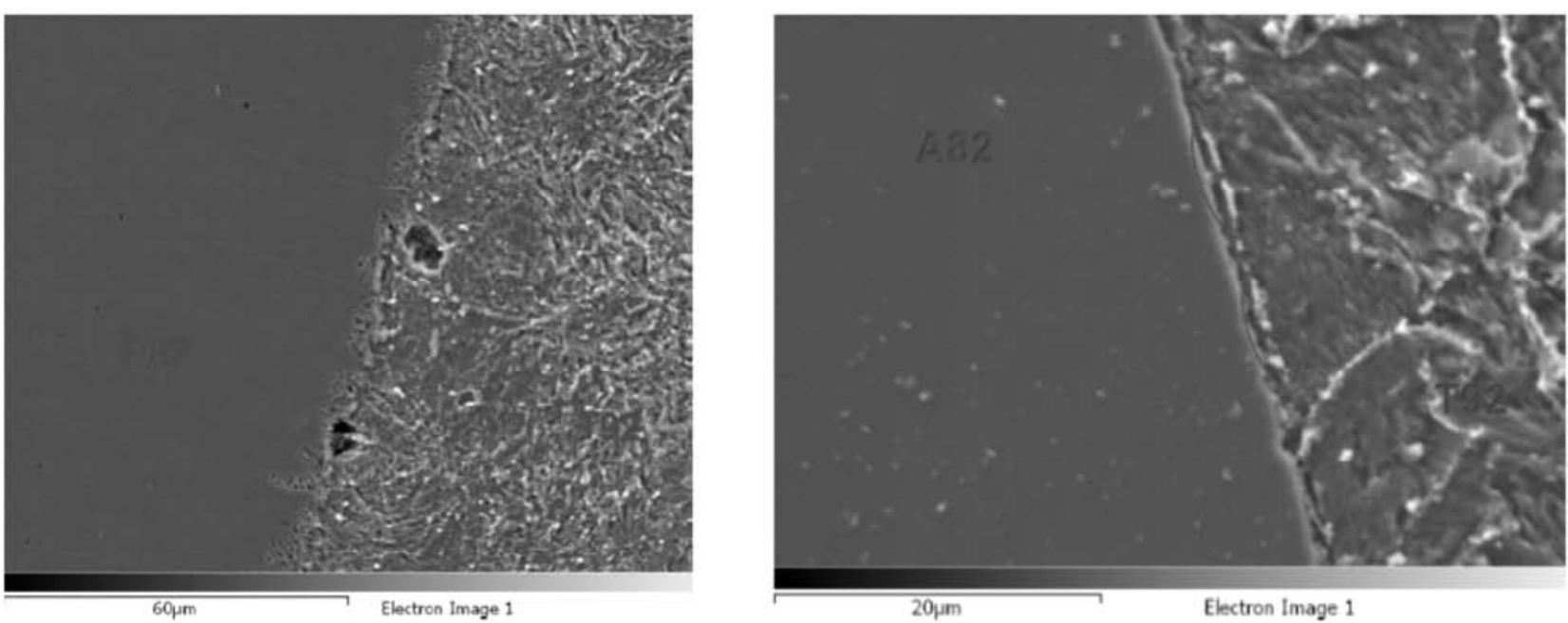

Figure 9: Specimen D (left): DMV304HCu/T92/P87-buttered-80Mpa/625 ${ }^{\circ} \mathrm{C} / 7654 \mathrm{~h}$ \& Specimen $\mathrm{E}$ (right): DMV310N/T92/A82-direct welding-80MPa / $625^{\circ} \mathrm{C} / 7311 \mathrm{~h}$

Slika 9. Epruveta D (levo) DMV304HCu/T92/P87-puterovan -80Mpa/625 ${ }^{\circ} \mathrm{C} / 7654 \mathrm{~h}$ i epruveta $E$ (desno): DMV310N/T92/A82-direktno zavarena-80MPa / $625^{\circ} \mathrm{C} / 7311 \mathrm{~h}$

\begin{tabular}{|c|c|c|c|c|c|c|}
\hline Specimen & $\begin{array}{c}\text { Filler metal } \\
\text { type }\end{array}$ & $\begin{array}{c}\text { Temperature } \\
{ }^{\circ} \mathrm{C}\end{array}$ & $\begin{array}{c}\text { Time @ T } \\
\mathrm{h}\end{array}$ & Type carbides & $\begin{array}{c}\text { Composition carbides } \\
\text { Type }\end{array}$ & Conditions \\
\hline DMV304HCu & P87 & 625 & 3000 & isolated & W-Cr-Mo & Direct welding/thermally aged \\
\hline A & A617 & 625 & 3000 & aligned & Cr-W-Mo & Direct welding/thermally aged \\
\hline B & A82 & 625 & 3005 & isolated & Cr-W-Mo & Direct welding/105 MPa \\
\hline DMV310N/HR3C
\end{tabular}

Table 8: Fusion line type and composition at 3000h

Tabela 8. Tip linije stapanja i sastav na $3000 \mathrm{~h}$

\begin{tabular}{|c|c|c|c|c|c|c|}
\hline Specimen & $\begin{array}{c}\text { Filler metal } \\
\text { type }\end{array}$ & $\begin{array}{c}\text { Temperature } \\
{ }^{\circ} \mathrm{C}\end{array}$ & $\begin{array}{c}\text { Time @ T } \\
\mathbf{h}\end{array}$ & Type carbides & $\begin{array}{c}\text { Composition carbides } \\
\text { Type }\end{array}$ & Conditions \\
\hline DMV304HCu & P87 & 625 & 7654 & isolated & W-Cr-Mo & buttered/80 MPa \\
\hline D & & & & & & Direct welding/80 MPa \\
\hline DMV310N/HR3C & A82 & 625 & 7311 & partly aligned & Cr-W-Mo & Do \\
\hline E & & & & & \\
\hline
\end{tabular}

Table 9: Fusion line type and composition at $7000 \mathrm{~h}$

Tabela 9. Tip linije stapanja $i$ sastav na $7000 \mathrm{~h}$

\begin{tabular}{|l|c|c|c|c|c|}
\hline Specimen & \multicolumn{1}{c}{ A } & B & C & D & E \\
\hline Filler metal & P87 & A617 & A82 & P87 & A82 \\
\hline Element & weight $\%$ & weight \% & weight \% & weight \% & weight \% \\
\hline V & 0.21 & 0.21 & 0.48 & 0,39 & 0,23 \\
Cr & 11.83 & 14.05 & 19.57 & 10,09 & 12,96 \\
Mn & 0.85 & 0.66 & 0.79 & 0,56 & 0,67 \\
Fe & 65.50 & 73.31 & 57.47 & 39,66 & 81,07 \\
Ni & 1.87 & 2.02 & 2.76 & 1,11 & 1,82 \\
Mo & 3.36 & 2.81 & 3.07 & 10,34 & 0,46 \\
W & 16.37 & 6.93 & 15.09 & 37,57 & 2,55 \\
\hline
\end{tabular}

Table 10: EDX analysis of fusion line carbides (type I) Tabela 10: EDX analiza karbida na liniji stapanja (tip I) 
The results at $3000 \mathrm{~h}$ (specimen $\mathrm{A}, \mathrm{B}$ and C-Table 8) show aligned carbides for fusion lines in DMWs using A617 filler metals (Figure 7). This correlates well with creep rupture testing results failed in the fusion line (Figure 1).

The DMWs using P87 and A82 type filler metals reveal isolated and partly aligned carbides respectively along the fusion lines (Figures $6 \& 8$ ). Although the composition measured by EDX is only semi-quantitative, there seems to be also a differentiation in compositional elements between the carbides of P87 and A617/A82 type filler metals as can be seen in Table 10. The fusion line carbides for P87 are W-Cr-Mo enriched while for A617/A82 rather Cr-W-Mo enriched.

The results at 7000h (specimen C and D-Table 9) for P87 and A82 type filler metals show isolated carbides for P87 but partly aligned for A82 (Figure 9). The compositional difference in carbides is more pronounced between the different types of filler metal demonstrating P87 differs from A617/A82 in the long term.

The P87 specimen $D$ fusion line carbides tend to be more enriched in $W$ than those using A617/A82. The $W$ enrichment was not found so far in DMW research but could be explained by the lack of $\mathrm{Ti}$ and lower levels of $\mathrm{Cr} / \mathrm{Nb}$ in the chemical analysis of P87 compared to A617/A82. Both $\mathrm{Ti}$ and $\mathrm{Nb}$ are strong carbide forming elements and compete with W available from the T92 base metal side.

\subsection{Creep ductility}

Low up to very low total strain at rupture $(<3 \%)$ and creep ductilities (RA\%) have been observed after creep rupture testing (see Table 11).

It looks like the buttering techniques are more ductile than the direct welds at least for the tempered DMWs.

The results for the re-normalized and tempered buttering technique are rather of a low level. It must be noted that differing stress levels might have influenced creep behavior. A lower range of creep ductility was also noted in the collaborative research between DMV304HCu and DMV310N/HR3C similar welds $(45.3-54.7 \%$ vs $19.3-25.4 \%$ ) at $177 \mathrm{MPa} / 650{ }^{\circ} \mathrm{C}$. The majority of the fracture locations in that case were situated in the base metal (T92).
Rezultati na 3000h (uzorak A, B i C-Tabela 8) pokazuju poravnane karbide za linije stapanja kod DMW koristeći A617 dodatni materijal (Slika 7). Ovo je u dobroj korelaciji sa rezultatima ispitivanja puzanja do loma na liniji stapanja (Slika 1).

DMW-ovi koji koriste P80 i A82 tipove dodatnih materijala otkrivaju izolovane i delimično poravnane karbide respektivno duž linije stapanja (slike 6 i 8). lako je sastav izmeren EDX-om samo polukvantitativan, čini se da postoji i diferencijacija u sastavu elemenata između karbida P80 i A617 / A82 dodatnih materijala kao što se vidi u Tabeli 10 . Karbidi linije stapanja za P87 su obogaćeni W-CrMo dok su za A617 / A82 obogaćeni Cr-V-Mo.

Rezultati na 7000h (uzorak C i D-Tabela 9) za dodatne materijale P87 i A82 pokazuju izolovane karbide za P87, ali delimično poravnane za A82 (slika 9). Razlika u sastavu karbida je izraženija među različitim tipovima dodatnih materijala, dok se P87 razlikuje od A617 / A82 na dugi rok.

Na epruveti D, karbidi linije stapanja P87 imaju tendenciju da budu više obogaćeni $W$ od onih koji koriste A617/A82. Obogaćivanje W nije pronađeno do sada $u$ istraživanju DMW, ali se moglo objasniti nedostatkom $\mathrm{Ti}$ i nižim nivoima $\mathrm{Cr} / \mathrm{Nb}$ u hemijskoj analizi P87 u poređenju sa A617/A82. I Ti i Nb su jaki karbidotvorci i dopunjavaju se sa $\mathrm{W}$ dostupnim sa strane T92 osnovnog materijala.

\subsection{Duktilnost pri puzanju}

Primećeni su niske do veoma niskih deformacija (izduženja) pri lomu (<3\%) kao i duktilnosti pri puzanju (RA\%) nakon ispitivanja puzanja do loma (vidi tabelu 11).

Izgleda da su tehnike puterovanja duktilnije od direktnih zavarivanja bar za žarene DMW.

Rezultati za ponovnu normalizaciju i žarenje tehnikom puterovanja su prilično niski. Treba napomenuti da su različiti nivoi napona uticali na ponašanje pri puzanju. Niži opseg duktilnosti pri puzanju takođe je primećen u kolaborativnom istraživanju između DMW304HCu i DMW310N / HR3C sličnih zavarenih spojeva $(45,3-54,7 \%$ naspram $19,3-25,4 \%$ ) na $177 \mathrm{MPa} / 650{ }^{\circ} \mathrm{C}$. Većina lokacija preloma u tom slučaju bile su u osnovnom materijalu (T92). 


\begin{tabular}{|l|l|c|c|c|c|c|c|}
\hline DMW & Filler metal & T $\left({ }^{\circ} \mathrm{C}\right)$ & $\sigma(\mathrm{Mpa})$ & $\mathrm{h}$ & Rupture & $\mathbf{A}(\%)$ & RA (\%) \\
\hline Direct Welding & & & & & & & \\
\hline HR3C/T92 & P87 & 625 & 80 & 5329 & T92HAZ & 1 & 18,8 \\
\hline DMV310N/T92 & A82 & 625 & 80 & 7311 & T92HAZ & 2,2 & 11,9 \\
\hline Buttering & & & & & & & \\
\hline DMV304HCu/T92 & A617/304HCu & 625 & 119 & 1790 & T92FL & 2,2 & 24,8 \\
\hline & P87/P87 (AW) & 625 & 119 & 1251 & T92HAZ & 1,5 & 28,9 \\
\hline & & 625 & 80 & 7654 & T92HAZ & 1,3 & 30,7 \\
\hline DMV304HCu/T92 (re-N\&T) & P87/P87 (AW) & 625 & 119 & 1184 & T92FL & 1,1 & 2,2 \\
\hline & & 625 & 80 & 8457 & T92FL & 0,7 & 16,8 \\
\hline
\end{tabular}

Table 11: Creep ductility after creep rupture testing for various DMW cases

Tabela 11. Duktilnost pri puzanju posle ispitivanja puzanja do loma za različite slučajeve DMW

\section{Discussion}

A617 base and weld metals are relaxation and hot cracking sensitive which makes them, although characterized by high creep strengths, the least valuable option for DMWs. It must be noted although that tube dimensions are normally not characterized by high levels of residual stress and, as a consequence, less susceptible to relaxation cracking. However, relaxation cracking depends on a wide range of external parameters which create local stress states that can initiate the mechanism. Here header-tube connections are certainly more susceptible than tube butt welds in loose $\mathrm{SH} / \mathrm{RH}$ bundles.

On the other hand, the high (overmatching) creep strength of A617 may concentrate high creep strain especially in the T92 fusion line and HAZ. On top of this, secondary hardening mechanisms (gamma prime) in A617 can even aggravate the situation.

Aging results at $3000 \mathrm{~h} / 625{ }^{\circ} \mathrm{C}$ conducted in the collaborative research projects [16] revealed an extreme hardening for direct welds using A617 filler metals. It points out that strains during creep/high temperature exposure are concentrated in the fusion line areas.

Direct welding requires a PWHT at $740-760^{\circ} \mathrm{C}$. The effect of a PWHT on austenitic steels however is by sensitization in the temperature range of about 450$850{ }^{\circ} \mathrm{C}$. It means that $\mathrm{Cr}$-depletion occurs at grain boundaries resulting in potential intergranular corrosion mechanisms. Although sensitization will occur naturally after longterm exposure at service temperatures, it renders the welds at an early stage particularly sensitive to abnormal conditions which might be the case during commissioning, incidents, repairs, co-combustion or transients. As such Intergranular Corrosion and Polythionic Acid or Chloride Induced SCC are potential risks. Specific precautions and attention need to be taken for avoiding any incident or contamination of the water/steam cycle quality. The research focusing on the fusion line formation of type I carbides,

\section{Diskusija}

Osnovni materijal i metal šava A617 su osetljivi na relaksacione (usled ponovnog zagrevanja) i vruće prsline koji in čini, iako in karakterišu visoke jačine puzanja, najmanje vrednom opcijom za DMW. Treba napomenuti da iako dimenzije cevi obično ne karakterišu visoki nivoi zaostalih napona i, kao posledica toga, manje su podložni prslinama pri otpuštanju. Međutim, nastanak prslina pri otpuštanju zavisi od širokog spektra spoljnih parametara koji stvaraju lokalne stresne tačke koje mogu pokrenuti mehanizam. Ovdje su priključci sa glavnim cevima sigurno više podložni od zavarivanja cevi u slobodnim SH / RH snopovima.

Sa druge strane, visoka (overmatching) čvrstoća puzanja A617 možeda koncentriše visoku deformaciju pri puzanju, naročito u liniji stapanja T92 i ZUT-u. Osim toga, mehanizmi sekundarnog očvršćivanja (gama prim) u A617 mogu čak pogoršati situaciju.

Rezultati starenja na $3000 \mathrm{~h} / 625{ }^{\circ} \mathrm{C}$ dobijeni u zajedničkim istraživačkim projektima [16] otkrili su ekstremno očvršćavanje kod direktnog zavarivanja pomoću A617 dodatnih materijala. Ona naglašava da su deformacije tokom puzanja / izlaganja visokim temperaturama koncentrisani u oblasti stsapanja.

Direktno zavarivanje zahteva PWHT na $740-760^{\circ} \mathrm{C}$. Međutim, efekat PWHT na austenitne čelikee je senzibilizacija u temperaturnom opsegu od oko 450-850 ${ }^{\circ} \mathrm{C}$. To znači da se Cr-izdvaja po granicama zrna što rezultuje potencijalnom interkristalnom korozijom. lako će se senzibilizacija odvijati prirodno nakon dugotrajne izloženosti na radnim temperaturama, čini se da su zavareni u ranoj fazi naročito osetljivi na nenormalne uslove kao prilikom puštanja u rad, incidenata, popravki, sagorevanja ili prelaza. Potencijalni rizici za izazivanje SCC (naponske prsline) su takva interkristalna korozija i politionska kiselina ili hloridi. Potrebno je preduzeti specifične mere opreza i obratiti pažnju kako bi se izbegao bilo koji incident 
responsible for premature cracking in the $F L$, reveals that formation of aligned linked up carbides is possible when using A617 filler metals for both buttered and direct welds (Figure 7). The fact that these type I carbides are not isolated, as is the case for P87 (Figure 6 \& 9), can give raise to creep cracking in the FL.

In order to compare results from creep rupture testing, one should strive to conduct long-term creep rupture testing involving durations in the order of $30 \mathrm{kh} \mathrm{min}$. Also the temperature and the stress levels play an important role. The temperature selected is a compromise between the higher creep properties of the advanced austenitics compared to the martensitic steel. In fact, the 625 ${ }^{\circ} \mathrm{C}$ is above the recommended temperature of $\mathrm{T} 92$ and could cause metallurgical instabilities. Due to the relatively short durations (10kh) the effect of thermal ageing under stress is not fully demonstrated. Extrapolations are necessary for lifetime assessments but, as such, take no microstructural instabilities into consideration.

On the other hand, creep rupture stress levels show a larger impact on the test results. High stresses could shift the fracture locations from the T92 HAZ for stresses below 140MPa towards the T92 base metal for stresses above $140 \mathrm{MPa}$, as observed by other researchers [13][14]. It is generally accepted that stress levels should be selected below the $140 \mathrm{MPa}$ level. In the course of the research projects, the most suitable stress level for the DMWs within the planned durations (10kh) appeared to be 80MPa.

LCF testing is not carried out in the projects unless a trial high temperature creep-fatigue test on a DMV304HCu/T92-P87 direct welded DMW. This trial fatigue test showed significant reduction in life (factor 4!) [10]. Further LCF component testing should give insight in the thermo-mechanical behavior of the welds as LCF testing remains an unavoidable tool for the assessment of DMWs in cycling operating condition.

Creep test results on DMW direct and buttered welds have shown very low elongations (total creep strains) at rupture i.e. from 0,7 up to $2,2 \%$. It is important to take these low elongations into consideration while creep damage prior to failure will not be preceded by a high degree of plastic deformation. Creep ductilities (RA\%) ranging from 2,2 to $18,8 \%$ were measured for direct and buttered re-N\&T DMWs compared to a range from 24.8 to $30.7 \%$ for the buttered and tempered DMWs. It means that the strains of the DMW compound, induced by primary axial creep stress and thermal stress originating from the differential thermal ili zagađenje u ciklusu voda / para.

Istraživanje koje se fokusira na formiranje karbida tipa I na linij i stapanja, odgovorno za prevremene prsline na liniji stapanja, otkriva da je formiranje povezanih karbida moguće pri upotrebi A617 dodatnih materijala i za puterovane i za direktno zavarene spojeve (slika 7). Činjenica da ovi karbide tipa I nisu izolovani, kao što je to slučaj kod P87 (Slika 6 i 9), može da poveća nastanak prslina na liniji stapanja.

Da bi se upoređivali rezultati ispitivanja puzanja do loma, trebalo bi sprovesti dugotrajno ispitivanje puzanja do loma u trajanju od $30 \mathrm{kh}$ minimum. Takođe, temperatura i nivo napona igraju važnu ulogu. Izabrana temperatura je kompromis između viših karakteristika puzanja naprednog austenitnog čelika u poređenju sa martenzitnim čelikom. Zapravo, $625{ }^{\circ} \mathrm{C}$ je iznad preporučene temperature za T92 i može izazvati metalurške nestabilnosti. Zbog relativno kratkih trajanja (10kh) efekat termičkog starenja pod naponom nije u potpunosti dokazan. Ekstrapolacije su neophodne za procene veka trajanja, ali kao takve ne uzimaju u obzir mikrostrukturne nestabilnosti.

S druge strane, nivoi napona pri puzanju pokazuju veći uticaj na rezultate. Visoki naponi mogu da prebace lokacije preloma iz ZUT T92 za napone ispod 140MPa prema osnovnom materijalu T92 za napone iznad $140 \mathrm{MPa}$, kao što su primetili drugi istraživači [13] [14]. Opšte je prihvaćeno da se nivoi napona biraju ispod nivoa 140MPa. Tokom istraživačkih projekata, najprikladniji nivo napona za DMW u planiranom trajanju (10kh) činilo se $80 \mathrm{MPa}$.

Ispitivanje LCF (niskociklični zamor) nije obavljeno u projektima, osim probnog visoko- temperaturnog ispitivanja puzanja/zamora na DMV304HCu /T92P87 direktno zavarenim DMW. Ovaj probni test zamora pokazao je značajno smanjenje u trajanju (faktor 4!) [10]. Dalja LCF ispitivanja komponenti trebalo bi da daju uvid u termo-mehaničko ponašanje zavarenih spojeva, jer ispitivanje LCF ostaje neizbežni alat za procenu DMW-a u uslovima radnog ciklusa.

Rezultati ispitivanja puzanja na DMW zavarenim direktno i puterovanjem pokazali su vrlo niska izduženja (ukupne deformacije pri puzanju) pri lomu tj. od 0,7 do $2,2 \%$. Važno je uzeti u obzir ove mala izduženja, jer oštećenju usled puzanja pre loma ne prethodi visok stepen plastične deformacije. Duktilnosti pri puzanju (RA\%) u rasponu od 2,2 do $18,8 \%$ izmerene su za direktne i puterovane renormalizovane i otpuštene DMW u poređenju sa opsegom od 24,8 do $30,7 \%$ za puterovane i žarene DMW. To znači da su deformacije DMW zavarenih 
expansion, are localized in the narrow (and weak) areas of the low alloy (T92) FGHAZ or FL.

\section{Conclusion}

The collaborative research projects on advanced stainless creep resisting steels provided several fundamental basic data on the behavior of DMWs as well as similar welds and base metals. Using different techniques and filler metals, it was possible to obtain an overview of the actual available methodologies.

The DMWs between martensitic and advanced austenitic stainless steels are an underestimated topic.

Experienced and documented premature failures demonstrates the criticality of DMWs. Therefore it is required to locate DMWs in design at areas of low stress and to avoid dissimilar wall thickness. On the other hand, the most recommended methodology for welding needs to be applied.

Based upon the results obtained and the current knowhow on DMWs related to tube welds by manual GTAW between martensitic and advanced austenitic stainless creep resisting steels, the following recommendations can be defined:

- Use of A617 filler metal is to be avoided due to its sensitivity to hot and relaxation cracking, unless a stabilization heat treatment $\left(980^{\circ} \mathrm{C} / 3 \mathrm{~h}\right)$ can be applied, as well as to potential premature creep failure due to type I carbide formation at the fusion line

- Direct welding incorporates a certain risk for intergranular corrosion or SCC of the austenitic stainless steel

- Buttering by P87 followed by a tempering PWHT is recommended above direct welding both from the standpoint of avoiding corrosion risks as well as improved creep rupture strength and creep ductilities. Other advantages of buttering techniques are that the critical areas (T92 HAZ) are welded while little restraint is present and afterwards stress relieved (PWHT) before the final weld is carried out. It must be realized however that buttering particularly for tube welding needs mechanization and as a consequence is a more expensive, complex and time-consuming fabrication process.

The importance of selecting the most suitable filler metal is also demonstrated. The P87 type filler metal so far confirms the earlier findings in EPRI spojeva, izazvani primarnim aksijalnim naprezanjem i termičkim naprezanjem koji potiču od različitog termičkog širenja, lokalizovani u uskim (i slabijim) područjima niskolegiranog čelika (T92) FGHAZ (finozrni ZUT) ili FL (linija stapanja).

\section{Zaključak}

Zajednički istraživački projekti na naprednim nerđajućim čelicima pružili su nekoliko temeljnih osnovnih podataka o ponašanju DMW-a, kao i sličnih zavarenih spojeva i osnovnih materijala. Koristeći različite tehnike i dodatne materijale, bilo je moguće dobiti pregled stvarnih dostupnih metodologija.

DMW između martenzitnih i naprednih austenitnih nerđajućih čelika su podcenjena tema.

Iskusni i dokumentovani preuranjeni lomovi pokazuju kritičnost DMW. Zbog toga je neophodno locirati DMW na projektu na područjima sa niskim naprezanjem i izbegavati različitu debljinu zida. Sa druge strane, treba primeniti najprihvatljiviju metodologiju zavarivanja.

$\mathrm{Na}$ osnovu dobijenih rezultata i trenutnog znanja o DMW vezanim za zavarivanje cevi ručnim TIG-om Između martenzitnih i naprednih austenitnih nerđajućih čelika otpornih na puzanje, mogu se definisati sledeće preporuke:

- Izbegavanje upotrebe A617 dodatnog materijala zbog njegove osetljivosti na vruće prsline i prsline pri otpuštanju, osim ako se može primeniti termička obrada - stabilizacija $\left(980^{\circ} \mathrm{C} / 3 \mathrm{~h}\right)$, kao i mogućnost prevremenog loma usled puzanja zbog formiranja karbida tipa I na liniji stapanja

- Direktno zavarivanje uključuje određeni rizik za interkristalnu koroziju ili SCC austenitnog nerđajućeg čelika

- Preporučuje se puterovanje P87 a zatim se preporučuje PWHT - žarenje iznad direktnog zavarivanja sa stanovišta izbegavanja rizika od korozije, kao i poboljšane čvrstoće puzanja pri lomu i duktilnosti pri puzanju. Druge prednosti tehnike puterovanja su da su kritična područja (T92 -ZUT) zavarena dok postoji mala krutost, a nakon toga se žare za smanjenje napona (PWHT) pre nego što se izvede konačni šav. Međutim, mora se shvatiti da puterovanje, posebno kod zavarivanja cevi, zahteva mehanizaciju i kao posljdica je skuplji, kompleksniji i dugotrajniji proces izrade.

Prikazan je i značaj izbora najpogodnijeg dodatnog materijala. Do sada je tip dodatnog materijala P87 potvrdio ranije nalaze u istraživanjima EPRI [7] [8] [9] i BWI/ Engie Lab projektima [10] [11]. Dodatni materiajli A82 mogu biti vredna alternativa, ali u dužim vremenima držanja, čini se da se na liniji 
research [7][8][9] and BWI/Engie Lab projects [10][11]. A82 filler metals might be a valuable alternative but at longer holding times, the fusion line seems to evolve in more aligned fusion line carbides. The project results however are based upon relatively short durations of thermal aging (3000h) and creep rupture testing (10kh). It allows to see trends in behavior and to make first extrapolations to feed life assessments but do not take long term microstructural instabilities into account. Therefore it is required to continue further long term differentiating and statistical work in future.

\section{Acknowledgment}

The authors would like to thank the Federal Government Department Public Services Economy and Engie for their financial support of the prenormative research projects. Also the industrial partners are gratefully acknowledged: NSSMC, Saltzgitter Mannesmann Stainless Tubes, Vallourec \& Mannesmann Tubes, Böhler Welding Group (Soudokay), Metrode for delivering base material and filler metals; Cockerill Mechanical Industries, Stork Technical Services, Cofely Fabricom GDF Suez, VCL for welding; AlBVinçotte for nondestructive examination and SIRRIS for chemical analysis.

Special thanks to Mr. M. Neyens (student at KUL University Leuven-MSc Welding Engineering) and to Dr. Ir. F. Vos (Materials Consult/KUL) as the author and co-promoter/reviewer respectively of the Master thesis which supplied valuable input for the project.

\section{References \\ 7.Literatura}

[1] Salzgitter Mannesmann Stainless Tubes-Boiler Grade DMV304HCU

[2] Salzgitter Mannesmann Stainless Tubes-Boiler Grade DMV310N

[3] A. Iseda, H. Okada, H. Semba and M. Igarashi, "Long-term creep properties and microstructure of

Super304H, TP347HFG and HR3C for advanced USC Boilers", 5th Int. Conference on Advances in Materials Technology for Fossil Power Plants, 3-5 October, 2008

[4] V. Friedmann and D. Siegele, "Damage behavior of nickel-based transition welds under cyclic thermomechanical loading", Materials at High Temperatures 27 pp. 35-43

[5] J.A. Penso, P. Belanger - "Mitigating failures in Ferritic-Austenitic Dissimilar Metal Joints in stapanja razvija više poravnanih karbida. Rezultati projekta su, međutim, zasnovani na relativno kratkim trajanjima termičkog starenja (3000h) i ispitivanju puzanja do loma (10kh). Ovo omogućava uvid u trendove ponašanja i pravljenja prve ekstrapolacije za ispunjenje procena veka trajanja, ali ne uzimaju u obzir dugoročne mikrostrukturne nestabilnosti. Zbog toga je neophodno nastaviti dalje dugoročno diferenciranje i statistički rad u budućnosti.

\section{Zahvalnost}

Autori se zahvaljuju Federalnom ministarstvu javnih službi i Engieu na njihovoj finansijskoj podršci prednormativnih istraživačkih projekata. Takođe su industrijski partneri kojima se izražava zahvalnost: NSSMC, Saltzgitter Mannesmann Stainless Tubes, Vallourec \& Mannesmann Tubes, Bohler

Grupa za zavarivanje (Soudokai), Metrode za isporuku osnovnog materijala i dodatnih materijala; Cockerill Mechanical Industries, Stork tehničke usluge, Cofeli Fabricom GDF Suez, VCL za zavarivanje; AlBVincotte za ispitivanje bez razaranja i SIRRIS za hemijsku analizu.

Posebna zahvalnost g. M. Neiensu (student na KUL Univerzitetu Leuven-MS Zavarivanje) i dr. Ir. F. Vos (Materials Consult / KUL) kao autoru i kopromoteru/recenzentu, na pristupu magistarskoj tezi koja je bila dragocen ulaz za projekat.

\section{Petrochemical Industry", ASME PVP 2013 (PVP2013-97550)}

[6] A. Omar, "Effects of Welding Parameters on Hard Zone Formation at Dissimilar Metal Welds", AWS Welding Journal February 1998 pp. 86s-93s

[7] J.A. Siefert, J.M. Sanders, J. M. Tanzosh, W.F. Newell Jr and J.P. Shingledecker, "Development of EPRI P87 solid wire", Materials at High Temperatures 27 pp. 243-252

[8] J.A. Siefert, J. M. Tanzosh, J.P. Shingledecker and W.F. Newell Jr, "EPRI P87: A Promising New Filler Metal for Dissimilar Metal Welding", AWS Welding Journal March 2011 pp. 30-34

[9] J. Shingledecker, K. Coleman, J. Siefert, J. Tanzosh and W. Newell, "High-Temperature 
Performance of a New Nickel-Based Filler Metal for Power Generation Applications" [10] BWI - New Generation Austenitic teels X10CrNiCuNb18-9-3 (Super 304H/DMV304HCu/TX304HB) - Weldability and high temperature properties - Technical Report [11] BWI - New Generation Austenitic Steels X6CrNiNbN25-20- Technical Report (in progress)

[12] KULeuven Master Thesis - Faculty Engineering Technology - "Dissimilar Metal WeldsImpact of type I/II carbides on creep life" (Academic Year 2014-2015)

[13] J. N. DuPont, "Microstructural evolution and high temperature failure of ferritic to austenitic dissimilar welds", International Materials Review 2012 (57) No 4 pp. 208-234

[14] EPRI TR 1019786 December 2011, Repair Methods for Dissimilar Welds-Development, Weldability and Properties of EPRI P87 Solid Wire Filler Metal [2920]

[15] EPRI CS-4252 November 1985, DissimilarWeld Failure Analysis and Development Program [4052]

[16] J. Vekeman, S. Huysmans and E. De Bruycker, "Weldability assessment and high temperature properties of advanced creep resisting austenitic steel DMV304HCu" - Welding in the World (2014) Vol. 58 pp. 873-882

[17] J. Vekeman, S. Huysmans and C. Hautfenne, "Weldability assessment and high temperature properties of advanced creep resisting austenitic steel X6CrNiNbN25-20 (DMV310N/HR3C)" - IIW Doc. Nr. IX-C-1049-15 (Helsinki 2015)

[18] D.I Roberts, R.H. Ryder and R. Viswananthan, "Performance of Dissimilar Welds in Service" Journal of Pressure Vessel Technology, August 1985 Vol. 107 pp. 247-254

[19] F.H. Ehrhardt, S.R. Holdsworth, I. Kühn and E. Mazza, "Creep fatigue crack development in dissimilar metal welded joints between steels and nickel based alloy", Materials Research Innovations 2013, Vol. 17 n5 pp. 327- 331

[20] J.D. Parker and G.C. Stratford, "Characterization of microstructures in nickel based transition joints", Journal of Materials Science 35 (2000) pp. 4099-4107

[21] Jian Cao, Yi Gong, Zhen-Guo Yang, Xiao-Ming Luo, Fu-Ming $\mathrm{Gu}$ and Zheng-Fei Hu, "Creep fracture behaviour of dissimilar weld joints between T92 martensitic and HR3C austenitic steels, International Journal of Pressure Vessels and Piping 88 (2011) pp. 94-98 